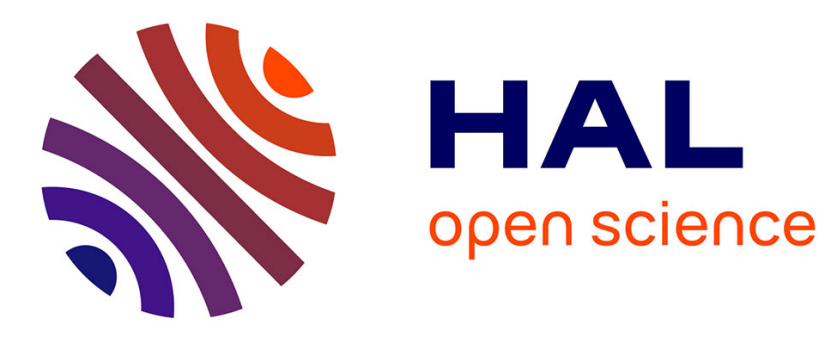

\title{
Genetic determinants associated with cfxA-positive clinical Capnocytophaga isolates
}

Zohreh Tamanai-Shacoori, Anais Dupont, Manon Auffret, Vincent Peton, Frédérique Barloy-Hubler, Elodie Ehrmann, Martine Ropert, Martine Bonnaure-Mallet, Anne Jolivet-Gougeon

\section{To cite this version:}

Zohreh Tamanai-Shacoori, Anais Dupont, Manon Auffret, Vincent Peton, Frédérique Barloy-Hubler, et al.. Genetic determinants associated with cfxA-positive clinical Capnocytophaga isolates. International Journal of Antimicrobial Agents, 2015, 46 (3), pp.356-358. 10.1016/j.ijantimicag.2015.05.006 . hal-01166301

\section{HAL Id: hal-01166301 https://hal-univ-rennes1.archives-ouvertes.fr/hal-01166301}

Submitted on 19 Nov 2015

HAL is a multi-disciplinary open access archive for the deposit and dissemination of scientific research documents, whether they are published or not. The documents may come from teaching and research institutions in France or abroad, or from public or private research centers.
L'archive ouverte pluridisciplinaire HAL, est destinée au dépôt et à la diffusion de documents scientifiques de niveau recherche, publiés ou non, émanant des établissements d'enseignement et de recherche français ou étrangers, des laboratoires publics ou privés. 
Genetic determinants associated with cfxA-positive clinical Capnocytophaga isolates

Zohreh Tamanai-Shacoori ${ }^{\mathrm{a}}$, Anais Dupont ${ }^{\mathrm{a}}$, Manon Auffret $^{\mathrm{a}}$, Vincent Peton ${ }^{\mathrm{a}}$,

Frédérique Barloy-Hubler ${ }^{\mathrm{b}}$, Elodie Ehrmann ${ }^{\mathrm{c}}$, Martine Ropert ${ }^{\mathrm{d}, \mathrm{e}}$, Martine Bonnaure-

Mallet $^{\text {a }}$, Anne Jolivet-Gougeon ${ }^{\mathrm{a}, \mathrm{d}, *}$ anne.gougeon@univ-rennes1.fr

${ }^{a}$ Equipe de Microbiologie, EA 1254, Université de Rennes 1, Université Européenne de Bretagne, 2 avenue du Professeur Léon Bernard, 35043 Rennes, France ${ }^{b}$ Plateforme Amadeus, Rennes, France

${ }^{c}$ Pôle Odontologie-CHU Nice, Faculté d'Odontologie, Université de Nice SophiaAntipolis, Nice, France

${ }^{d}$ Pole Biologie-CHU Rennes, 2 rue Henri Le Guilloux, 35033 Rennes, France

${ }^{e}$ INSERM U991, 35000 Rennes, France

<PA>Equipe de Microbiologie, EA 1254, Université de Rennes 1, 2 avenue du Professeur Léon Bernard, 35043 Rennes, France. Tel.: +33 223234305 fax: +33223234913

Sir,

Capnocytophaga spp. have a role in the pathogenesis of various forms of periodontal disease and systemic infections, particularly severe in neutropenic cancer patients. The prevalence of $\beta$-lactam-resistant oral bacteria is increasing in clinical isolates [1]. All of the reported $\beta$-lactam-resistant Capnocytophaga isolates are $\beta$-lactamase-producers, but minimum inhibitory concentrations (MICs) for the different $\beta$-lactams are variable [2]. The objective of the current study was therefore 
to explain the variability in $\beta$-lactam MIC profiles in $31 c f x A$ gene-positive oral Capnocytophaga spp. clinical isolates with various antibiotypes. This study investigated: (i) the presence of other $\beta$-lactamase genes in addition to cfxA (bla cepA/cblA and cfiA); (ii) the expression level of $c f x A$ in representative isolates with different antibiotic phenotypes; and (iii) the potential causes of $c f x A$ expression variability, including mutation(s) in $c f x A$ genes, location of the $c f x A$ gene on a plasmid or the chromosome, and detection of the prevalence of mobile genetic determinants [mobA, oriT, repA, ISCoc1 and transposons (Tn)] described as being involved in cfxA mobilisation and dissemination in Capnocytophaga spp. strains.

All 31 isolates were clearly identified as Capnocytophaga gingivalis $(n=1)$, Capnocytophaga spp. $(n=1)$, Capnocytophaga ochracea $(n=2)$, Capnocytophaga granulosa $(n=3)$, Capnocytophaga leadbetteri $(n=3)$, Capnocytophaga AHN9576/AHN9798/AHN8471/ChDc/ ChDCOS43 $(n=4)$ and Capnocytophaga sputigena $(n=17)$ by $16 \mathrm{~S}$ rRNA gene sequencing. $\mathrm{MIC}_{90}$ and $\mathrm{MIC}_{50}$ values (MICs that inhibit $50 \%$ and $90 \%$ of the isolates, respectively) were all $>256 \mathrm{mg} / \mathrm{L}$ for amoxicillin and first-and second-generation cephalosporins but were variable for third-generation cephalosporins. This variation in MICs for $\beta$-lactams was not due to the concomitant presence of other resistance genes: the $c e p A / c b / A$ and $c f i A$ genes were never detected, and the bla $a_{\mathrm{CSP}-1}$ gene [3] was amplified in 11/31 (35\%) of $c f x A$ positive Capnocytophaga isolates (Fig. 1). The presence of blacsp-1 was not significantly associated with higher MICs of cefotaxime [MIC $>16 \mathrm{mg} / \mathrm{L}$ according to Clinical and Laboratory Standards Institute (CLSI) breakpoints (http://clsi.org/)] compared with the presence of $c f x A$ only $(P>0.1)$. In four isolates, MICs of $\beta$ lactams were low (range, $<0.016-2 \mathrm{mg} / \mathrm{L}$ ) with a negative nitrocefin test, despite a 
positive cfxA PCR. In 29/31 isolates, the presence of 966 bp corresponding to the complete sequence of $c f x A$ was detected (27 isolates were $\beta$-lactam-resistant but 2 were $\beta$-lactam-susceptible). PCR assay, sequencing and in silico analysis showed that the $\mathrm{CfxA} \mathrm{COOH}$-terminal region (C-ter) in two susceptible isolates was replaced by a glycosyltransferase ( $96 \%$ homology) for one and with a partial hypothetical efflux pump (98\% homology) for the other, with 16-bp and 82-bp overlapping gene sequences, respectively. Replacement of the whole C-ter region of $c f x A$ was linked to $\beta$-lactamase gene inactivation, despite a positive $c f x A$ PCR in the 5 ' region. Of note, the C-ter region of $c f x A$ appeared to be a preferentially targeted area or 'hotspot' for the acquisition of foreign genetic material.

Among the clinical isolates, $52 \%$ harboured plasmids of $3.5,5$ and/or $9 \mathrm{~kb}$. PCR amplified Tn (77.4\%), ISCoc1 (61.3\%), repA (54.8\%) and mobA (74.2\%) that was related to plasmid detection $(P<0.05)$. This was not the case for the oriT gene $(16.1 \%)(P>0.1)$ (Supplementary Table S1). In the cfxA-positive Capnocytophaga isolates, mobA and repA genes were mainly detected (100\% and $94 \%$, respectively, among plasmid-positive isolates) and related to plasmid detection $(P<0.05)$. In $74 \%$ of $m o b A$-positive isolates, the $m o b A$ and $c f x A$ region were linked by a $96-b p$ intergenic sequence mainly found in plasmid-positive strains $(P<0.01)$. Higher MICs of cefotaxime (MIC > $4 \mathrm{mg} / \mathrm{L}$ ) [Comite de l'Antibiogramme de la Société Française de Microbiologie (CA-SFM) 2013; http://www.sfm-

microbiologie.org/page/page/showpage/page_id/90.html] were significantly related to the presence of $\operatorname{mobA}(P=0.0002)$, mobA-cfxA junction $(P=0.0015), \operatorname{rep} A(P=$ $0.0003)$ and at least one plasmid in bacterial strains $(P<0.0001)$. The presence of blacsP-1, oriT, ISCoc1 or Tn did not significantly influence the MICs of cefotaxime. 
blacSP-1 was detected on the chromosome or a plasmid and in different species of Capnocytophaga, indicating a large diffusion of this novel extended-spectrum $\beta$ lactamase among oral Capnocytophaga spp.

An unchanged complete $c f x A$ sequence in two $\beta$-lactam-susceptible isolates indicated a possible misexpression of this gene under the influence of the cfxA genetic environment. Gene copy number as the only explanation of the expression variability of $\operatorname{cf} x A$ has already been observed [4].

The presence of the 96-bp junction mobA-cfxA sequence could be important for optimal expression of the $c f x A$ gene. Higher MICs of $\beta$-lactams were related to $c f x A$ overexpression arising from IS integration upstream of the coding sequence [5]. The diversity of plasmid profiles of Capnocytophaga isolates did not favour dissemination of several different $\beta$-lactam resistance genes via a single plasmid. In the current study, the cfxA gene could be located on a plasmid or/and the chromosome, whatever the species or MIC of $\beta$-lactams.

The numerous genetic rearrangements in the $c f x A$ gene and the presence of various genetic mobile elements in oral Capnocytophaga suggest that this genetic site might be a reservoir for antibiotic resistance genes and their spread among different species. Furthermore, maintenance of this gene, even in an inactive form, might contribute to the persistence of antibiotic resistance genes in the oral flora.

Acknowledgments: The authors thank Jeremy Violette, Nolwenn Oliviero and Hélène Solhi for technical assistance; Philippe Gautier for help with the sequence 
analysis; and Adina Pascu for editorial assistance. This work was supported by the Conseil régional de Bretagne (France).

Funding: None.

Competing interests: None declared.

Ethical approval: Not required.

\section{References}

[1] Ehrmann E, Handal T, Tamanai-Shacoori Z, Bonnaure-Mallet M, Fosse T. High prevalence of $\beta$-lactam and macrolide resistance genes in human oral Capnocytophaga species. J Antimicrob Chemother 2014;69:381-4.

[2] Jolivet-Gougeon A, Tamanai-Shacoori Z, Desbordes L, Burggraeve N, Cormier M, Bonnaure-Mallet M. Genetic analysis of an Ambler class A extended-spectrum $\beta$-lactamase from Capnocytophaga ochracea. J Clin Microbiol 2004;42:888-90.

[3] Guillon H, Eb F, Mammeri H. Characterization of CSP-1, a novel extendedspectrum $\beta$-lactamase produced by a clinical isolate of Capnocytophaga sputigena. Antimicrob Agents Chemother 2010;54:2231-4.

[4] García N, Gutiérrez G, Lorenzo M, García JE, Píriz S, Quesada A. Genetic determinants for cfxA expression in Bacteroides strains isolated from human infections. J Antimicrob Chemother 2008;62:942-7. 
[5] Rogers MB, Bennett TK, Payne CM, Smith CJ. Insertional activation of cepA leads to high-level $\beta$-lactamase expression in Bacteroides fragilis clinical isolates. J Bacteriol 1994;176:4376-84. 
Fig. 1. Detection of blacsp-1, $m o b A, c f x A-m o b A$ (junction), oriT, repA, transposons (Tn), ISCoc1 and plasmids (presence of at least one plasmid) according to different species in clinical cfxA-positive Capnocytophaga isolates. 
134 FIG 1. The bla CSP-1, $, m_{0 b A}, c f x A-m o b A$ (junction), oriT, repA, $T n$, ISCoc1 genes and 135 plasmid detection (presence of at least one plasmid), according to different species in 136 clinical cfxA-positive Capnocytophaga isolates.

137

138

139

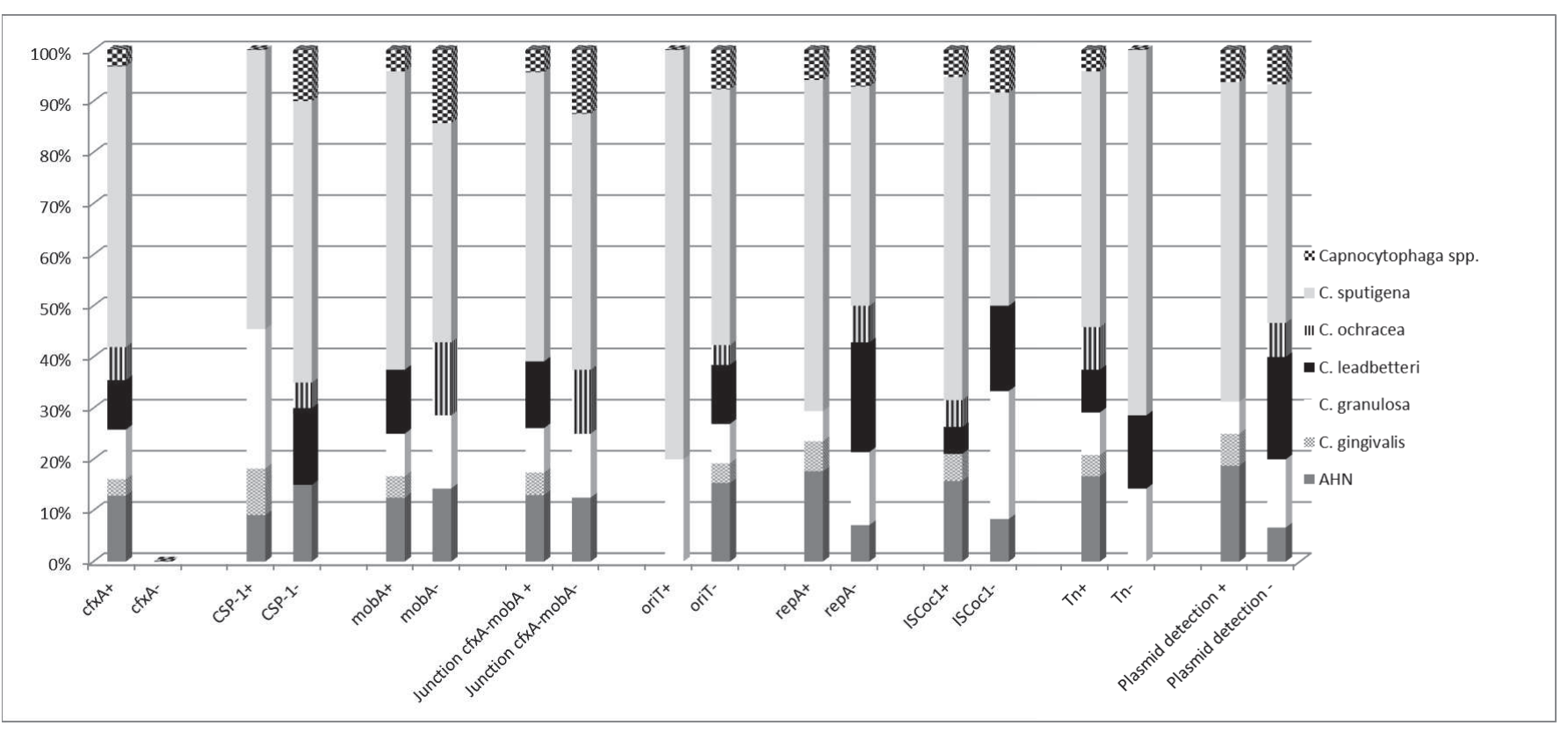

140

141

142

143 